\title{
A preliminary study to define limits of active learning strategy effectiveness in physics courses
}

\section{Prof. C. Bauer-Reich, University of Jamestown}

Cherish Bauer-Reich is the Chair of the Engineering Department at University of Jamestown in Jamestown, ND, and is a senior member of IEEE. She earned a B.S. in physics and M.S. in electrical engineering, both from North Dakota State University. She also earned an M.S. in earth science from University of Minnesota-Twin Cities.

\section{Dr. Katrina Christiansen, University of Jamestown}

Katrina Christiansen worked in industry as the Director of Malting Technology at Intelligent Malt for 4 years. She worked in malting research and development at Cargill Malt for 4 years. She completed her PhD in Agricultural Engineering at Iowa State University in 2011. She worked as a plant engineer for a bioenergy company after completing her Master's and Bachelors in Biosystems Engineering at the University of Nebraska-Lincoln. 


\title{
A preliminary study to define limits of active learning strategy effectiveness in physics courses
}

\author{
C. Bauer-Reich, K. L. Christiansen \\ cherish.bauerreich@uj.edu, katrina.christianse@uj.edu \\ Department of Engineering \\ University of Jamestown
}

\begin{abstract}
While active learning has been shown in several studies to be more effective approach to developing student learning than the traditional lecture format, ambiguities exist about the effectiveness of flipped classes. In this preliminary study, we show that there are conditions when flipped classrooms are effective and others where they are not. The study uses data collected from two sets of courses: the first set is algebra-based physics courses for upper-level biology and exercise science majors, while the second is a calculus-based physics courses for freshman engineering majors and upper-level pre-professional students. Students were evaluated using the Force Concept Inventory and the Conceptual Survey of Electricity and Magnetism. The results indicate that flipped classes are generally more useful for freshman, while upper-level students appear to find lecture courses more effective. Specific practices used in both the flipped and lecture-based courses will be discussed in detail.
\end{abstract}

\section{Introduction}

Physics courses are usually pre-requisites for many engineering courses. They are required not only to introduce the mathematics of the physical systems which students will encounter in engineering courses but also as a way to develop and improve problem-solving skills.

On the whole, physics education research tends to show that active learning strategies are more effective than traditional lecture in creating student engagement and increasing student gain as measured by various assessments. ${ }^{1}$

One method often discussed in the literature is peer learning techniques, often exemplified by "think-pair-share". ${ }^{2}$ "Think-pair-share" is a technique where the instructor poses a question to the students and then asks them to think about it before discussing with other students. After the discussion, students share their answers with the class, allowing the instructor to gauge how well the students understand the concept. If students understood the concept, the instructor can move to another topic. If they did not, then the instructor can spend additional time on the topic to ensure better understanding. Selection of questions posed to the students may determine the 
effectiveness of this method. ${ }^{3}$

Another method is the "flipped classroom." "In this model, introduction of the concepts is provided prior to entering the classroom, normally in the form of videos. Students then spend their time in the classroom working on problems to develop higher thinking skills, improve their conceptual understanding, and remove misconceptions about foundational concepts.

Generally speaking, both methods are types of interactive engagement. While some studies have found that flipped classrooms are more effective than peer instruction during interactive lecture, at least one study has found no difference. ${ }^{5}$

Our goal in this analysis is to determine if one or the other of these methods was more effective as well as discuss possible reasons for the differences in certain student populations.

\section{Methods}

\section{Course demographics}

The study was performed by using students from 100-level courses in algebra-based physics and 200-level courses in calculus based physics. These courses typically had very different make-ups.

The 100-level courses primarily consisted of 3rd and 4th year biology and exercise science students. The mechanics course is Physics 143 and the electromagnetics and optics course is Physics 144.

Typically, these students are exposed to statistics at the university level and sometimes trigonometry. However, these students are typically the ones who have successfully completed the first couple years of university and have developed study skills. The gender distribution ranged between one-half and three-quarters female. Enrollment in College Physics I, which focused on mechanics was between 20 and 30 students per semester. College Physics II, which focused on was often smaller and composed primarily of students who intended to move on to graduate study in biology or physical therapy. These classes were smaller and had between 15 and 20 students.

The 200-level students who enrolled in Physics I and Physics II were most often 1st or 2nd year engineering majors, with 10-20 per semester. There were usually between 2 and 6 students from biology, chemistry, or biochemistry who planned to pursue professional programs in medicine, dentistry, or optometry. These students were often 3rd or 4th year students. Additionally, 1-2 math or math education students may also be enrolled in this course, most often in the 1st or second year. Most students who took Physics I also took Physics II unless they chose to change majors or transfer out of the university. The students were almost all males with varying levels of math preparation before taking the courses, although Calculus I was a co-requisite. Physics 203 is the mechanics course, and Physics 204 is the electromagnetic and optics course.

\section{Comparison of teaching methods}

There were three different methods used in the assessed courses. 
- Interactive Lecture - Because of the small class sizes, most classes are interactive and taught with more focus on discussion. In some cases, "think-pair-share" was used as an explicit tool for in-class engagement. An example would be to discuss a topic and then pose a question to the students. The students then think individually for a short period of time and then discuss their idea with another student. After a few minutes, the students share what they believe the answer is and the professor can use this as feedback to determine if they've understood the topic before moving on. These courses often assigned homework outside the class, although this may or may not be graded or turned in. Assessment was most often performed with quizzes.

- Flipped Classroom - Videos on concepts was provided outside of class. These videos often utilized premade content such as Crash Course Physics or Flipping Physics. A quiz had to be taken prior to class covering material from the selected videos and textbook. Students spent class time covering conceptual questions and exercises as groups. The groups would solve problems and then, as a class, discuss the solution or present their solution at the white board. Students were also expected to do additional homework for credit outside of class.

- Problem-Based Lectures - These classes used a lecture format. Rather than discussing concepts, the lectures primarily involved the instructor solving problems in front of the class and introducing concepts through these problems. No homework was assigned, but students were quizzed on the problems given in class. Typically, students would receive a quiz problem out of 8-10 potential problems presented over a two-day period.

\section{Assessment Tools}

Four different assessment tools were used to determine student learning. Physics 143 and Physics 203 utilized the Force Concept Inventory (FCI). ${ }^{6}$ Physics 144 and Physics 204 used the Conceptual Survey of Electricity and Magnetism (CSEM) ${ }^{7}$ Both instruments were administered twice during the semester: the first time was during the first week of class, and the second time was during the last week of class.

The FCI focuses on a conceptual understanding of Newtonian mechanics while minimizing the use of mathematics and technical jargon. The FCI offers the advantage of being a highly researched tool that, as a whole, has high reliability, although individual questions lack that reliability. ${ }^{8}$ )

Student evaluation scores, on a 4-point Likert Scale, were also provided as a way to examine student perceptions of and satisfaction with the learning environment. It is important to note that the response rate for evaluations was usually significantly lower than the number of students who took the assessments.

\section{Mathematical Methods}

Unweighted averages were used to quantify results from student evaluations.

The FCI and CSEM were evaluated both using normalized gain and Cohen's d, also referred to as effect size. Our scores were from matched populations, so data from students who did not 
complete both the pre- and post-test were excluded from the data set. Studies have shown that normalized gains will show greater gains in student populations with higher pre-test scores. ${ }^{1,9} \mathrm{We}$ therefore included data on effect size, as that removes the bias for lower pre-tests often observed in the 100-level courses as well as minimizing the impact of differing class sizes.

\section{Drawbacks}

We would like to explicitly draw attention to two major drawbacks of this study. First and foremost, we do not have statistically significant sample sizes. Our student body is small, and, as such, enrollment in these classes is small as well. This leads to the second drawback which is that we have no control group.

We acknowledge that this study is not definitive research into physics education. We intended this to be a source, however, for other researchers who have access to larger student populations.

The advantages we do have is that the groups taking these courses are relatively homogeneous in a way that a large classroom generally is not. Our students are generally from the midwest region and have a relatively uniform socioeconomic and educational background. We have attempted to use this homogeneity to tease out some confounding issues with the hope that other researchers will be able explore these observations.

\section{Results}

The following tables provide data from each of the classes taught using the different methods. Data from the flipped classroom model is shown in Table 1, from the problem-based lectures in 2, and from the interactive lectures in 3 .

The clearest trend in the data indicates that that the interactive lecture is the least effective method of instruction. It is more difficult to discern the differences between the problem-based lectures and flipped classroom, however.

Using the normalized gain, it appears that the problem-based lecture format was more effective for 100-level courses and the flipped classroom was more effective for the 200-level courses. When we examine effect size as a measure of learning, this relationship does not hold, and it appears that the problem-based lectures were more effective for mechanics instruction while the flipped classroom was equally or more effective for electromagnetics concepts.

Students in the 200-level courses appeared to be more satisfied with the flipped class model compared with either the interactive or problem-based lectures. The 100-level courses appeared to prefer the problem-based lectures.

\section{Discussion}

There are some small differences between types of instruction and the level of class when examining performance. It appears that the 200-level students, who were often freshmen, preferred the flipped classroom while the upper-level biology students preferred the problem-based lectures. 


\begin{tabular}{cccccc}
\hline Course & $\begin{array}{c}\text { No. of } \\
\text { Students }\end{array}$ & Assessment & $\begin{array}{c}\text { Normalized } \\
\text { Gain }\end{array}$ & $\begin{array}{c}\text { Effect } \\
\text { Size }\end{array}$ & $\begin{array}{c}\text { Evaulation } \\
\text { Score }\end{array}$ \\
\hline Phys 143 & 17 & FCI & 0.18 & 1.02 & 3.13 \\
Phys 203 & 18 & FCI & 0.32 & 1.13 & 3.44 \\
& & & & & \\
Phys 144 & 16 & CSEM & 0.05 & 0.75 & 2.86 \\
Phys 204 & 9 & CSEM & 0.28 & 1.83 & 3.4 \\
\hline
\end{tabular}

Table 1: Results from Flipped Classroom

\begin{tabular}{cccccc}
\hline Course & $\begin{array}{c}\text { No. of } \\
\text { Students }\end{array}$ & Assessment & $\begin{array}{c}\text { Normalized } \\
\text { Gain }\end{array}$ & $\begin{array}{c}\text { Effect } \\
\text { Size }\end{array}$ & $\begin{array}{c}\text { Evaulation } \\
\text { Score }\end{array}$ \\
\hline Phys 143 & 25 & FCI & 0.30 & 1.69 & 3.25 \\
Phys 203 & 17 & FCI & 0.30 & 1.39 & 2.55 \\
& & & & & \\
Phys 144 & 19 & CSEM & 0.08 & 0.76 & 3.56 \\
Phys 204 & 11 & CSEM & 0.17 & 1.44 & 2.95 \\
\hline
\end{tabular}

Table 2: Results from Problem-Based Lectures

\begin{tabular}{cccccc}
\hline Course & $\begin{array}{c}\text { No. of } \\
\text { Students }\end{array}$ & Assessment & $\begin{array}{c}\text { Normalized } \\
\text { Gain }\end{array}$ & $\begin{array}{c}\text { Effect } \\
\text { Size }\end{array}$ & $\begin{array}{c}\text { Evaulation } \\
\text { Score }\end{array}$ \\
\hline Phys 203 & 13 & FCI & 0.21 & 0.94 & 2.39 \\
Phys 204 & 13 & CSEM & 0.15 & 1.10 & 2.6 \\
\hline
\end{tabular}

Table 3: Results from Interactive Lectures 
It is difficult to determine which method was more effective as it depends on which measure is used for evaluation. Both methods were also superior to the interactive lecture format, which the 200-level students appeared to dislike as much as the problem-based lectures.

Students in the 100-level classes are generally more mature, have better study skills, and seemed to appreciate the clear expectations about what they needed to learn for class. They felt that the framework of the problem-based lectures more clearly defined their expectations and they seemed more able to study for quizzes and exams. Despite the fact that they saw fewer problems, they accomplished more according to both measurements in this format. When utilizing the flipped-classroom model, students seemed more frustrated with the model, often verbalizing that they had to "teach themselves."

In contrast, the students in the 200-level classes were still developing study skills and appeared to have much lower scores on quizzes in the problem-based lecture setting. They also seemed to be frustrated more easily when encountering challenges. One comment that was made frequently in class and in evaluations is that problems on the exams were different than those in class. The flipped classroom model may be more effective for these students because it helped them to more effectively structure their study time outside of class while improving their problem-solving skills in class.

On some level, the flipped classroom appears to be more effective in younger/newer students. This may not be true of older/more successful students, but attitude about presentation style may be a factor. Older students may have better developed study skills. Additionally, many of these students come from fields which require a significant amount of memorization, and the problem-based lectures appear to enable them to use that strength; memorizing how to do problems seemed effective in helping these students to develop a better conceptual understanding of physics.

These observations may also generate questions regarding the assessment methods.

\section{Conclusion}

Both a flipped classroom and a problem-based lecture format were more effective than interactive lecture in helping students to improve their conceptual understanding of physics. The two methods could be seen as having advantages for certain situations depending on the measurement method, but a definite difference in student satisfaction was noted between the groups based on instructional style. Students at the 100-level from biology and exercise science backgrounds preferred a problem-based lecture while students from engineering seemed to prefer a flipped classroom.

\section{References}

[1] David E Meltzer and Ronald K Thornton. Resource letter alip-1: active-learning instruction in physics. American journal of physics, 80(6):478-496, 2012. 
[2] Frank Lyman. Think-pair-share: An expanding teaching technique. Maa-Cie Cooperative News, 1(1):1-2, 1987.

[3] Rica Sirbaugh French and Edward Prather. Uncovering the unknown unknowns of peer instruction questions. In Physics Education Research Conference Proceedings, volume 2018, 2018.

[4] Cynthia Brame. Flipping the classroom. Vanderbilt University Center for Teaching, 2013.

[5] Darryl Yong, Rachel Levy, and Nancy Lape. Why no difference a controlled flipped classroom study for an introductory differential equations course. Primus, 25(9-10):907-921, 2015.

[6] David Hestenes, Malcolm Wells, and Gregg Swackhamer. Force concept inventory. The physics teacher, 30(3): 141-158, 1992.

[7] David P Maloney, Thomas L OKuma, Curtis J Hieggelke, and Alan Van Heuvelen. Surveying students conceptual knowledge of electricity and magnetism. American Journal of Physics, 69(S1):S12-S23, 2001.

[8] Nathaniel Lasry, Steven Rosenfield, Helena Dedic, Ariel Dahan, and Orad Reshef. The puzzling reliability of the force concept inventory. American Journal of Physics, 79(9):909-912, 2011.

[9] Jayson M Nissen, Robert M Talbot, Amreen Nasim Thompson, and Ben Van Dusen. Comparison of normalized gain and cohen's d for analyzing gains on concept inventories. Physical Review Physics Education Research, 14 (1):010115, 2018. 